\title{
Integrated assessment of biomarker responses and comparative toxicity pathway in snails Bellamya aeruginosa exposed to tributyltin and triphenyltin in sediments
}

\author{
Lingling $\mathrm{Wu}^{1,2}$, Ling Chen ${ }^{1,2}$, Lingjiao Zhu ${ }^{1,2}$, Xiaoping Chen ${ }^{1,2}$ and Qian $\mathrm{Li}^{1,2^{*}}$ (1)
}

\begin{abstract}
Background: Sediments function as a secondary and significant source of tributyltin (TBT) and triphenyltin (TPT) in aquatic ecosystems and may pose a potential threat on benthic organisms and human health. The subchronic toxicity of sediment-associated TBT or TPT to snails Bellamya aeruginosa at environmentally relevant concentrations was investigated in this study. Multiple endpoints at the biochemical [ethoxyresorufin-O-deethylase (EROD), superoxide dismutase (SOD), catalase (CAT), protein carbonyl content (PCC) and lipid peroxidation (LPO)] and transcriptomic levels were examined.
\end{abstract}

Results: TBT or TPT in sediment could induce antioxidant enzymes' activities and result in oxidative damage in the hepatopancreas of B. aeruginosa after 28-day exposure. A transcriptomic profile of B. aeruginosa exposed to TBT and TPT was reported. CYP genes and EROD activity were sensible and reliable biomarkers for toxicity assessment of TBT or TPT in sediments. Comparative pathway analysis revealed the alteration of steroid hormone biosynthesis and retinol metabolism in B. aeruginosa after 90-day exposure to sediment-associated TBT at the concentration of $2000 \mathrm{ng} / \mathrm{g} \mathrm{dw}$, which might affect both reproduction and lipogenesis functions. The ubiquitin proteasome system and immune system might be the toxicity target in B. aeruginosa after exposure to sediment-associated TPT for 90 days.

Conclusions: The results offered new mechanisms underlying the toxicity of sediment-associated tributyltin and triphenyltin.

Keywords: Tributyltin, Triphenyltin, Sediments, Bellamya aeruginosa, Biomarkers, RNA sequencing, Toxicity pathways

\section{Background}

Two organotin compounds, tributyltin (TBT) and triphenyltin (TPT), have been widely used as fungicides in agricultural activities and as ingredients of antifouling paints since the 1960s [1]. They are potent endocrine disruptors, which may cause developmental malformations in oyster, death of mussels and deformation of gastropod

\footnotetext{
*Correspondence: 1410389@tongji.edu.cn

${ }^{1}$ Key Laboratory of Yangtze River Water Environment, Ministry of Education, College of Environmental Science and Engineering, Tongji University, Shanghai 200092, China

Full list of author information is available at the end of the article
}

after aqueous exposure in ng/L concentrations [2,3]. Due to their high toxicity and persistency, the application of TBT-based antifouling paints has been prohibited by the International Maritime Organization. However, TPT compounds are still used as contact fungicides to protect crops. Despite the amount of TBT and TPT directly released into the aquatic ecosystem from antifouling paints has been greatly reduced, their concentrations in marine sediments and organisms remain high in several coastal areas with frequent shipping activities and agricultural activities, which results in various local ecological problems [4-7]. In costal systems, sedimentary 
concentration levels of TBT were reported as ranging from 9 to $469 \mathrm{ng} / \mathrm{g}$ dw from Jinhae Bay in Korea [8], and from 0.3 to $174.7 \mathrm{ng} / \mathrm{g} \mathrm{dw}$ at the ports of Xiamen, Shantou and Huiyang in China [9]. Chen et al. [10] found that sediment samples from the Estuarine Turbidity Maxima zone of the Yangtze Estuary had the TBT levels above $10 \mathrm{ng} / \mathrm{g} \mathrm{dw}$, which are sufficient to bring harmful effects to benthic organisms and pose serious ecological risks. The organotin compounds' contamination was demonstrated to vary slightly during the year 2014-2016 in the Yangtze Estuary [10]. It is expected that the TBT and TPT effects will be present in marine environments and freshwater ecosystems for some years ahead [11]. The sediments may act as a secondary and significant source of TBT and TPT pollution for aquatic ecosystems [12], which may pose a potential threat to aquatic organisms.

Benthic organisms play an essential role in aquatic ecosystems and may be good bioindicators of sedimentbound contaminants. The deposit-feeding benthic gastropods are exposed to organotin compounds through direct contact with sediments and ingestion of sediment particles [13]. Gastropod snails have been demonstrated to be exceptional test organisms for the assessment of endocrine-disrupting effects, such as effects on reproduction and development, defeminization and masculinization, decreased fertility, hatching success, or hermaphroditism [14-16]. The superimposition of male sexual characteristics onto females ("imposex") in response to organotin pollution occurs on more than 260 species of gastropods worldwide, while there are 42 species that are unaffected even though they are exposed to high aqueous TBT or TPT concentrations $[17,18]$. The snail Bellamya aeruginosa (Gastropoda, Caenogastropoda, Viviparidae) is a widely distributed species that can be found in Chinese rivers, lakes and ponds and has great importance for human consumption $[19,20]$. This organism is closely related to surficial sediments, where it burrows in the surface layer and consumes particulate organic matters in sediments. As a result, it might be greatly exposed to sediment-bound organotin compounds. B. aeruginosa has been reported to be relatively sensitive to different sorts of anthropogenic pollutants [21], which makes it as a test species for sediment toxicity assessments.

Biochemical biomarkers are widely applied to determine the ecotoxicity of many contaminants and might give insights into the underlying toxic mechanisms [22]. The exposure of aquatic organisms to organic compounds results in phase-I biotransformation reactions (i.e., monoxygenation), which would lead to the production of reactive oxygen species (ROS) [23]. The antioxidant system includes various enzymes such as superoxide dismutase (SOD), which catalyzes the conversion of superoxide radical $\left(\mathrm{O}_{2}^{-}\right)$to hydrogen peroxide $\left(\mathrm{H}_{2} \mathrm{O}_{2}\right)$, and catalase (CAT), which reduces $\mathrm{H}_{2} \mathrm{O}_{2}$ to $\mathrm{H}_{2} \mathrm{O}$. The failure of antioxidant defenses to counteract ROS-mediated damage may lead to significant oxidative stress such as lipid peroxidation and protein carbonyl formation [24]. The increase in lipid peroxidation (LPO) and protein carbonyls content (PCC) have been employed as biomarkers to indicate oxidative stress induced by organic contaminants [25]. The application of such multiple biochemical parameters is more advantageous than the use of only one parameter and is demonstrated to get better acquainted with the physiological responses of the organisms to the contamination [26].

Omic approaches have been extensively applied for toxicity evaluation and mechanism studies [27, 28]. Recent developments in high-throughput sequencing (HTS), particularly in the field of RNA sequencing (RNAseq) and de novo assembly technology, have provided a way to analyze alternations in gene expression patterns across whole transcriptomes of non-model species [29, 30]. RNA sequencing has been applied to several aquatic organisms, such as roach Rutilus rutilus [30], the Pacific oyster Crassostrea gigas [31] and green mussel Perna viridis [32] for studying their transcriptomic responses to environmental stress. In toxicology, comparative transcriptome analysis functioned as a powerful approach to improve the discovery of novel biological effects, including the differential expression patterns of genes, toxicity pathways and adaptation mechanisms [33, 34]. Zhang et al. [35] have demonstrated that the profile of hepatic genes of rare minnow (Gobiocypris rarus) was up-regulated in the steroid biosynthesis pathway and downregulated in the retinol metabolism pathway after TBT exposure for 60 days.

In the present study, snails Bellamya aeruginosa were employed to assess the effects of the sediment-associated tributyltin or triphenyltin at environmentally relevant concentrations on the benthic organisms. The responses in hepatic antioxidant defense system through a wide range of biochemical parameters were investigated, and the changes in transcriptome profile using the RNA sequencing approach were examined. The aims were to better understand the toxic mechanism of sedimentassociated tributyltin and triphenyltin at environmentally relevant concentrations on snails $B$. aeruginosa after the subchronic exposure.

\section{Materials and methods Reagents and chemicals}

Tributyltin chloride (TBTCl; CAS number 1461-22-9) and triphenyltin chloride (TPTCl; CAS number 334267-4) were obtained from Merck Schuchardt Chemicals, Germany, with a purity of greater than $97 \%$. A stock 
solution of TBT chloride and TPT chloride was prepared by dissolving $\mathrm{TBTCl}$ and $\mathrm{TPTCl}$ in acetone and stored at $4{ }^{\circ} \mathrm{C}$ in the dark before experiments. The commercial reagent kits of total protein, superoxide dismutase (SOD), catalase (CAT), lipid peroxidation (LPO), and protein carbonyl content (PCC) were obtained from SigmaAldrich, USA. Other analytical grade reagents and chemicals were purchased from Aladdin Reagent Co., Ltd.

\section{Test organisms}

Bellamya aeruginosa (length $20.56 \pm 1.28 \mathrm{~mm}$ and weight $3.23 \pm 0.44 \mathrm{~g}$ ) raised in lab were applied as the test organisms. Snails were acquired from a pond in the Wuhan Botanic Garden of the Chinese Academy of Sciences, and the pond was believed to be free of pollution $[21,36]$. They were acclimated in the laboratory at a temperature of $24 \pm 1{ }^{\circ} \mathrm{C}$ and under a 24-h light-dark cycle in a 70-L $(50 \mathrm{~cm} \times 40 \mathrm{~cm} \times 35 \mathrm{~cm})$ glass aquarium for more than 3 months before the experiment. The acclimation freshwater with a hardness concentration of $250 \mathrm{mg} / \mathrm{L}$ and a $\mathrm{pH}$ value of $7.5 \pm 0.5$ was aerated with an air pump. Ground aquarium fish food (Sanyuan ${ }^{\circledR}$, Beijing, China) were selected to feed snails. No initial tributyltin and triphenyltin concentrations were detected in the snails and fish food.

\section{Sediment spiking}

The natural sediments used for all treatments were acquired from Dehang Nature Reserve located in Hunan Province, China [37]. Coarse particles were removed from wet sediments by passing through a nylon filter of $150 \mu \mathrm{m}$ and supernatant water was decanted after thoroughly settlement. Then the sediments were kept under a temperature of $80{ }^{\circ} \mathrm{C}$ overnight to remove undesired fauna and then homogenized [37]. The pretreated sediments were stored at $4{ }^{\circ} \mathrm{C}$ until sediment spiking. Notably, the sieved sediment had no background concentrations of tributyltin and triphenyltin.

Four exposure concentrations (100, 500, 1000, and $2000 \mathrm{ng} / \mathrm{g}$ ) for either TBT or TPT were chosen according to the environmentally relevant concentrations in sediments in this study. The experiments were conducted in 5-L glass aquarium. Each treatment contained $600 \mathrm{~g}$ of dry sediments. Prepared TBT or TPT stock solutions were added into sediment samples and homogenized by stirring. Control groups were set without any additional pollutants in sediments. In the solvent control group, acetone was added at the concentration of $0.03 \%$. Three replicates were set for each treatment and control groups. All sediments were kept in darkness for a month to ensure chemical equilibrium between the sediment samples and the water [38]. Organotin levels in sediments were quantified according to the method described by Chen et al. [39] to ensure the validation of exposure.

\section{Exposure experiment and sampling}

Four liters of overlying water (Milli-Q water) were gradually supplied to the sediments of each glass aquarium. All chambers were aerated and allowed to settle for $48 \mathrm{~h}$ before the introduction of snails. Exposure experiments were carried out under static conditions with aeration. The test conditions were identical to the acclimation conditions. Each glass aquarium was covered with plastic wrap to avoid the moisture evaporation. The subchronic exposure period lasted for 28 days in total. Eventual mortality in each treatment was recorded and dead snails were counted and removed. Nine snails were collected from each treatment group on day $0,7,14$ and 28 . A careful dissection was performed on snails and the hepatopancreas was separated from the visceral mass, which was snap-frozen with liquid nitrogen immediately and stored at a temperature of $-80{ }^{\circ} \mathrm{C}$ for further biochemical analysis. To capture an organismal-level and temporally representative transcriptomic response to TBT or TPT contamination, the remaining snails were continuously exposed until 90 days and collected for RNA extraction. All experiments were conducted in conformity to guidelines approved by the Animal Ethics Committee at Tongji University.

\section{Biochemical analysis}

The homogenates of hepatopancreas tissue were prepared according to Li et al. [36] for the determination of biochemical parameters. Total protein concentrations were detected using the total protein kit (Sigma-Aldrich, USA) in accordance with the Bradford method. The activities of all biochemical biomarkers were determined with assay kits from Sigma-Aldrich following the manufacture's protocols. All biomarker responses were measured by BioTek Synergy 4 multi-mode microplate reader (BioTek, USA). The ratio of specific enzyme activity from treated snail samples to specific enzyme activity of the controls was expressed as an index, the relative enzyme activity (REA) [40].

Statistical analyses of data were performed with IBM SPSS version 19.0. Biomarker results pertaining to ethoxyresorufin-O-deethylase (EROD), SOD, CAT, LPO and PCC were checked for normality and variance homogeneity using the Shapiro-Wilks and the Levene test, respectively. Analysis of variance (ANOVA) followed by a Dunnett's test was performed to compare statistical differences of biochemical parameters between treatment and control groups. The significance level was set at $p<0.05$ and $p<0.01$ for all tests performed. 


\section{RNA sequencing}

Snails from the control, $2000 \mathrm{ng} / \mathrm{g}$ TBT exposure group and $2000 \mathrm{ng} / \mathrm{g}$ TPT exposure group were collected for RNA isolation and the RNA samples would be applied for sequencing and library preparation. Snail samples were frozen in liquid nitrogen and total RNA was extracted from samples following the instructions of the Trizol ${ }^{\circledR}$ reagent (Invitrogen, USA). RNA quality was examined with $2 \%$ agarose gel and the concentration was measured with a Nanodrap spectrophotometer (NanoDrop, USA).

RNA-seq transcriptome library was constructed in

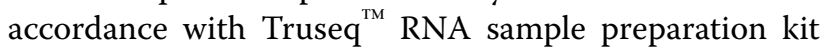
(Illumina, USA). Messenger RNA was isolated following the polyA selection method and then fragmented. Double-stranded cDNA was synthesized with a SuperScript double-stranded cDNA synthesis kit (Invitrogen, USA) and random hexamer primers (Illumina, USA). The synthesized cDNA was subjected to end-repair, phosphorylation and 'A' base addition in accordance with the protocol of Illumina's library construction. The fragments of 200-300 bp were selected for the libraries and amplified with Phusion DNA polymerase for 15 PCR (polymerase chain reaction) cycles. Finally, the libraries were sequenced on the Illumina HiSeq 4000 platform. The cDNA libraries were constructed and sequenced by Shanghai Majorbio Bio-Pharm Technology (Shanghai, China). There were $60,657,066,60,160,828$ and $61,357,620$ clean reads produced from the control group, TBT exposure group and TPT exposure group, respectively. Approximately $91.29 \%, 92.14 \%$ and $91.84 \%$ of reads met the quality requirement and the quality percentage values were above $\mathrm{Q} 30 \%$.

Neither the genome nor the transcriptome of $B$. aeruginosa has been characterized previously. Therefore, a reference transcriptome of $B$. aeruginosa was assembled from all the sequencing reads acquired in the present study. Prior to assembly, raw paired-end reads in FASTQ format were processed using SeqPrep (https:/githu b.com/jstjohn/SeqPrep) and Sickle (https://github.com/ najoshi/sickle) software. Clean reads were acquired after removing adapter sequences, reads with poly- $\mathrm{N}(>10 \%)$ and low-quality raw reads. Sequences less than $20 \mathrm{bp}$ in length were eliminated from read libraries. The paired reads from each of both two samples were merged in order that any overlapping reads were combined into a single read. De novo assembly was carried out with the merged reads and unmerged paired-end reads from each of the two sequence libraries using the Trinity software (http://trinityrnaseq.sourceforge.net/). The minimum length of a contig was set to $201 \mathrm{bp}$. The open reading frame (ORF) of each unisequence was also predicted using Trinity software. A total of 111,202 transcripts were obtained for the reference transcriptome database of $B$. aeruginosa. All transcripts were clustered into 74,513 unigenes, the average size of which was $1286 \mathrm{bp}$.

Gene function was annotated against the NCBI nonredundant protein sequences (NR), STRING, the Swissprot database, and Kyoto Encyclopedia of Genes and Genomes (KEGG) using BLASTX with a typical $E$ value threshold of less than $1.0 \times 10^{-5}$. Functional annotation by gene ontology (GO) terms was analyzed using BLAST2GO software (http://www.blast2go.com/b2gho $\mathrm{me})$. The unigene sequences were functionally annotated by the NR $(26,056)$, Swissprot $(12,869)$, KEGG $(14,656)$ and String $(5797)$ databases with a cut-off $E$ value $<1.0 \times 10^{-5}$.

\section{Differential gene expression and pathway analysis}

To identify differentially expressed genes (DEGs) between the control and treatment group, the expression level of each transcript was calculated following the fragments per kilobase of exon per million mapped reads (FRKM) method. Gene abundances were quantified with RSEM (RNA-seq by expectation-maximization). The analysis for DEGs between the control and treatment group was performed with the edgeR software package [41]. A fold change $\geq 2$ and a false discovery rate (FDR) $<0.05$ were set as the threshold for the DEGs caused by TBT or TPT exposure. Metabolic pathway analysis was carried out according to the Kyoto Encyclopedia of Genes and Genomes (KEGG, http://www.genome.jp/kegg/). KEGG pathway enrichment analysis of DEGs was conducted with Goatools software and KOBAS program. A $p$ value $<0.05$ was regarded as the threshold for significant enrichment [42].

\section{Results}

\section{Biomarker responses}

EROD changes induced by tributyltin and triphenyltin

The EROD changes of the hepatopancreas in B. aeruginosa after 7-day, 14-day and 28-day exposure to sediment-associated tributyltin (TBT) and triphenyltin (TPT) are shown in Fig. 1. Snails exposed to $100 \mathrm{ng} / \mathrm{g}$ sediment-associated TBT showed a significant $(p<0.05)$ increase of relative EROD activity at day 7 and day 28 than the control group. The REA of EROD challenged with $500 \mathrm{ng} / \mathrm{g}$ TBT increased significantly at day 28 $(p<0.05)$. The REA of EROD in $1000 \mathrm{ng} / \mathrm{g}$ TBT group increased significantly at day 14 and day $28(p<0.05$ and $p<0.01$, respectively). Snails exposed to $2000 \mathrm{ng} / \mathrm{g}$ TBT showed a significant $(p<0.01)$ enhancement of relative EROD activity at day 14 and day 28 than the control group. $2000 \mathrm{ng} / \mathrm{g}$ TBT increased the EROD activity by 2.71-fold of the control group at day 28. Snails exposed to $100 \mathrm{ng} / \mathrm{g}$ and $2000 \mathrm{ng} / \mathrm{g}$ sediment-associated TPT exhibited a significant increase of relative EROD activity 

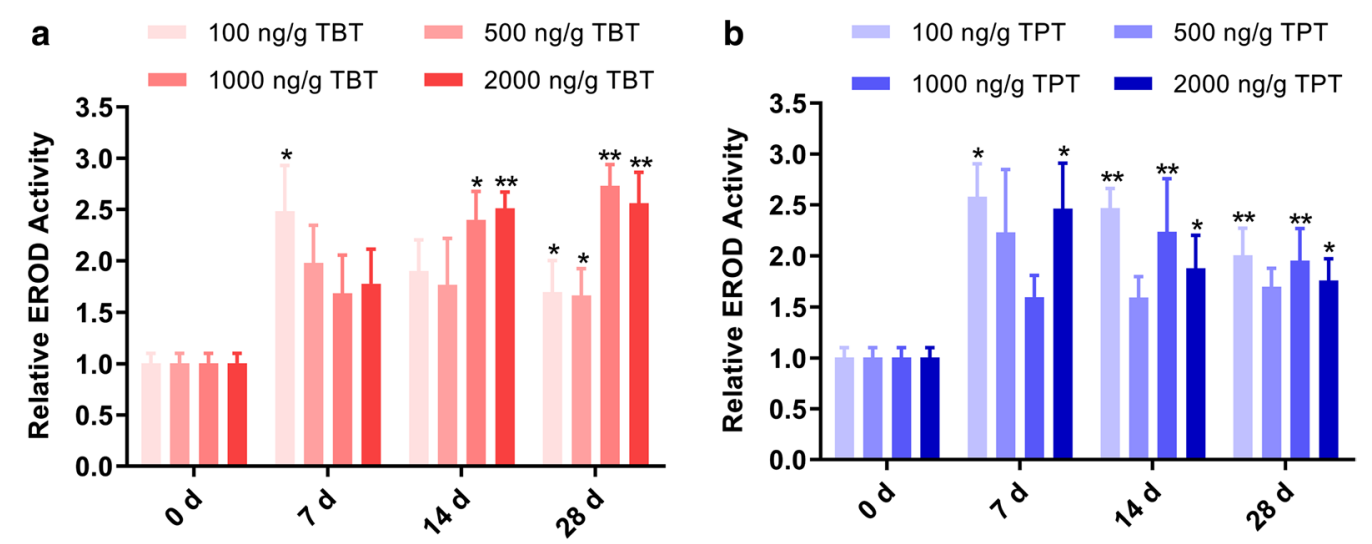

Fig. 1 Relative enzymatic activity (REA) of ethoxyresorufin-O-deethylase (EROD) in the hepatopancreas of Bellamya aeruginosa exposed to sediment-associated tributyltin (a) and triphenyltin (b) of 100, 500, 1000 and $2000 \mathrm{ng} / \mathrm{g}$. Results are mean \pm SD. Asterisks indicate significant difference from the control $(p<0.05)$; double asterisks indicate significant difference from the control $(p<0.01)$

at day 7, 14 and 28 than the control group. The REA of EROD activity in $500 \mathrm{ng} / \mathrm{g}$ TPT group did not reveal a significant difference during the exposure period. Snails exposed to $1000 \mathrm{ng} / \mathrm{g}$ TPT treatment group exhibited a significant $(p<0.01)$ increase of relative EROD activity at day 14 and 28. $2000 \mathrm{ng} / \mathrm{g}$ TPT exposure increased the EROD activity by 1.81 -fold of the control group at day 28 .

\section{Antioxidant enzyme responses after exposure to triphenyltin and triphenyltin}

The relative SOD and CAT activities of the hepatopancreas in B. aeruginosa after 7-day, 14-day and 28-day exposure to sediment-associated tributyltin (TBT) and triphenyltin (TPT) are shown in Fig. 2. The REA of SOD in $100 \mathrm{ng} / \mathrm{g}$ TBT group did not reveal a significant difference during the exposure period. Snails exposed to $500 \mathrm{ng} / \mathrm{g}$ and $1000 \mathrm{ng} / \mathrm{g}$ sediment-associated TBT showed a significant increase of relative SOD activity with the exposure duration than the control group and the relative SOD activity increased before day 14 and then decreased at day 28. The REA of SOD in $2000 \mathrm{ng} / \mathrm{g}$ TBT group increased significantly during the exposure period than the control group and the relative SOD activity increased at day 7 following decreased at day 14 and day 28. Snails exposed to $100 \mathrm{ng} / \mathrm{g}$ and $2000 \mathrm{ng} / \mathrm{g}$ sediment-associated TPT showed a significant increase of relative SOD activity at day 7, 14 and 28 than the control group. REA of SOD activity in snails challenged with $500 \mathrm{ng} / \mathrm{g}$ TPT was significantly increased at day 14 and 28. Snails exposed to $1000 \mathrm{ng} / \mathrm{g}$ TPT treatment group exhibited a significant $(p<0.01)$ increase of relative SOD activity with the exposure duration and reached its maximum level at day 28. Snails exposed to all TBT treatment or TPT treatment groups showed a significant $(p<0.01)$ enhancement of relative CAT activity with the exposure duration than the control group. After a 28-day exposure, $2000 \mathrm{ng} / \mathrm{g}$ TBT and TPT treatment resulted in significant increases of CAT activities by 2.44- and 3.42-fold compared with the control group, respectively.

\section{Oxidative stresses after exposure to triphenyltin and triphenyltin}

The relative LPO and PCC levels of the hepatopancreas in B. aeruginosa after 7-day, 14-day and 28-day exposure to sediment-associated tributyltin (TBT) and triphenyltin (TPT) are shown in Fig. 3. The REA of LPO level in $100 \mathrm{ng} / \mathrm{g}$ and $2000 \mathrm{ng} / \mathrm{g}$ TBT group did not reveal a significant difference during the exposure period. Snails exposed to $500 \mathrm{ng} / \mathrm{g}$ sediment-associated TBT showed a significant $(p<0.05)$ enhancement of relative LPO level at day 28 than the control group. The REA of LPO level in $1000 \mathrm{ng} / \mathrm{g}$ TBT group increased significantly $(p<0.01$ and $p<0.05$, respectively) at day 14 and day 28 . The REA of LPO level in snails challenged with $100 \mathrm{ng} / \mathrm{g}$ TPT increased significantly $(p<0.05)$ at day 14 and recovered to the control level at day 28 . The relative LPO level in snails exposed to $500 \mathrm{ng} / \mathrm{g}$ TPT increased significantly $(p<0.05)$ at day 14 and 28. Snails exposed to $1000 \mathrm{ng} / \mathrm{g}$ sediment-associated TPT showed a significant $(p<0.05)$ enhancement of relative LPO level at day 28 than the control group. The REA of LPO level in $2000 \mathrm{ng} / \mathrm{g}$ TPT group increased significantly $(p<0.01)$ at day 14 . The relative PCC level in snails exposed to $100 \mathrm{ng} / \mathrm{g}$ TPT significantly $(p<0.05)$ increased at day 14 and day 28 . Snails exposed to 500, 1000 and $2000 \mathrm{ng} / \mathrm{g}$ TBT or TPT exhibited a significant increase of relative PCC level with the exposure duration than the control group. 

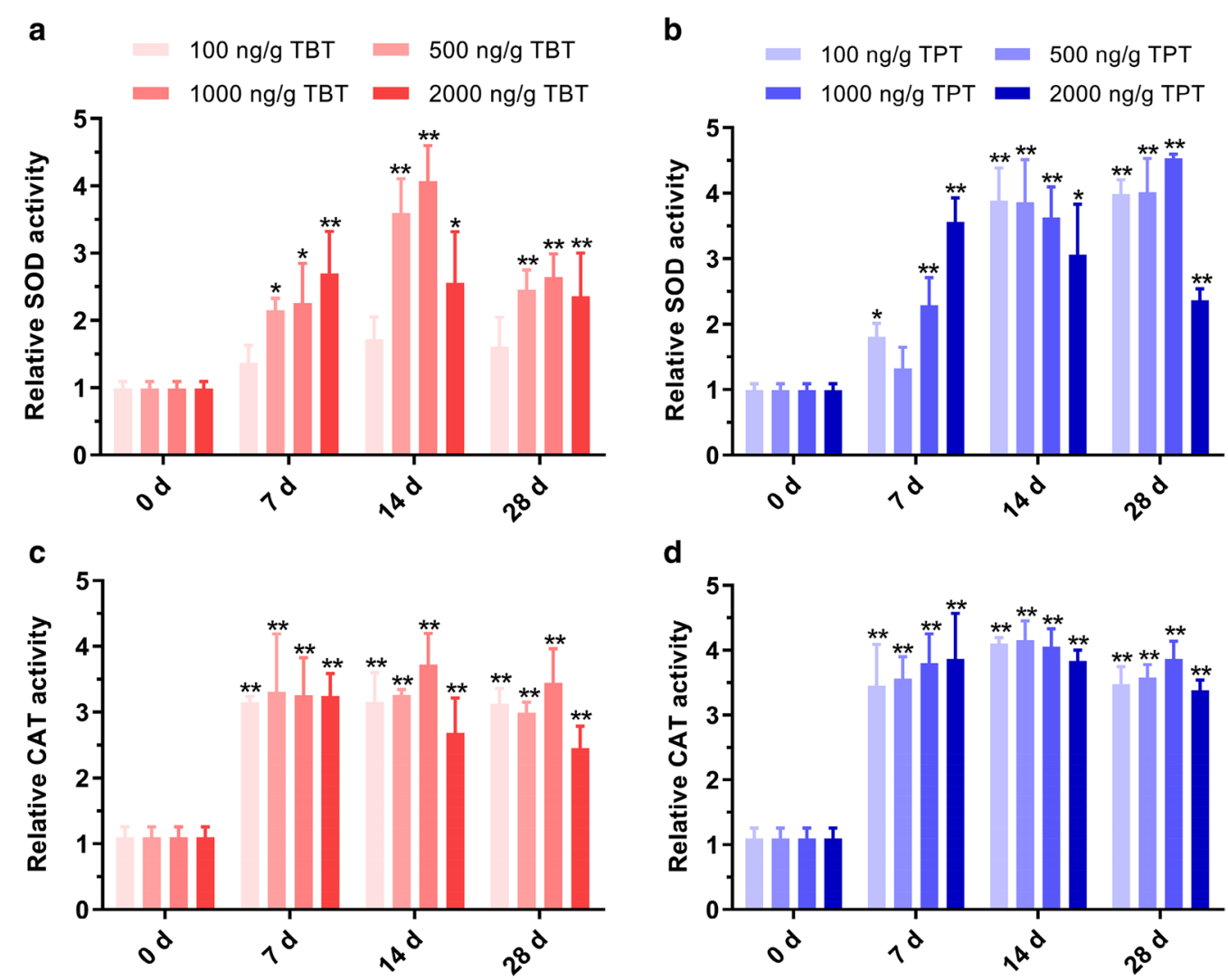

Fig. 2 Relative enzymatic activity (REA) of superoxide dismutase (SOD) in the hepatopancreas of Bellamya aeruginosa exposed to sediment-associated tributyltin (a) and triphenyltin (b) of 100, 500, 1000 and $2000 \mathrm{ng} / \mathrm{g}$. Relative enzymatic activity (REA) of catalase (CAT) in the hepatopancreas of Bellamya aeruginosa exposed to sediment-associated tributyltin (c) and triphenyltin (d) of 100, 500, 1000 and $2000 \mathrm{ng} / \mathrm{g}$. Results are mean \pm SD. Asterisks indicate significant difference from the control $(p<0.05)$; double asterisks indicate significant difference from the control $(p<0.01)$

\section{DEGs and KEGG pathway after exposure to tributyltin and triphenyltin}

A total of 392 DEGs were identified for TBT treatment group. 171 DEGs were up-regulated with a range of $\log _{2}$ FC from 3.78 to 10.45 , while the remaining 221 DEGs were down-regulated with a range of $\log _{2} \mathrm{FC}$ from -11.93 to -2.64 . The annotation could be performed on 123 DEGs with functional descriptions (data shown in Additional file 1). Up-regulated and down-regulated DEGs from TBT treatment group and control group were exhibited in a volcano plot, which is given in Additional file 2.

KEGG pathway analysis was conducted for biological elucidation of DEGs. Total 36 annotated DEGs for TBT treatment group were functionally assigned to 11 KEGG pathways (Fig. 4). Among these KEGG pathways, the pathways of the Steroid hormone biosynthesis (ko00140), Retinol metabolism (ko00830) and Chemical carcinogenesis (ko05204) were demonstrated to be significantly enriched. Additional file 3: Table S1 and
Fig. S1 exhibits the profile of genes which were up-regulated in the pathway of steroid hormone biosynthesis induced by sediment-associated TBT in B. aeruginosa. Genes up-regulated include alcohol sulfotransferase (SULT2B1, EC:2.8.2.2), 17beta-estradiol 17-dehydrogenase (HSD17B1, EC:1.1.1.62), cytochrome P450 family 1 subfamily A polypeptide 1 (CYP1A1, EC:1.14.14.1), cytochrome P450 family 3 subfamily A (CYP3A, EC:1.14.14.1) and cytochrome P450 family 3 subfamily A polypeptide 4 (CYP3A4, EC:1.14.13.32). Additional file 3: Table S2 and Fig. S2 exhibits the profile of genes up-regulated in the retinol metabolism pathway induced by sediment-associated TBT in $B$. aeruginosa. Up-regulated genes include cytochrome P450 family 1 subfamily A polypeptide 1 (CYP1A1, EC:1.14.14.1), cytochrome P450 family 3 subfamily A polypeptide 4 (CYP3A4, EC:1.14.13.32) and cytochrome P450 family 3 subfamily A polypeptide 5 (CYP3A5, EC:1.14.14.1).

A total of 1430 DEGs were identified for $2000 \mathrm{ng} / \mathrm{g}$ TPT exposure group. 562 DEGs were up-regulated with 


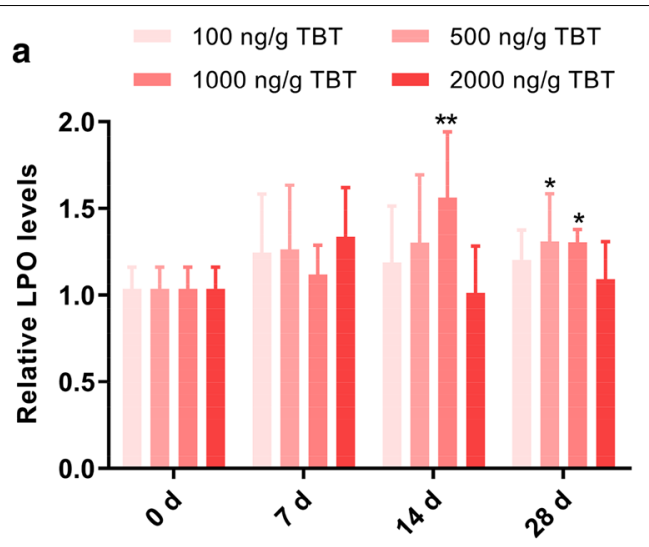

C

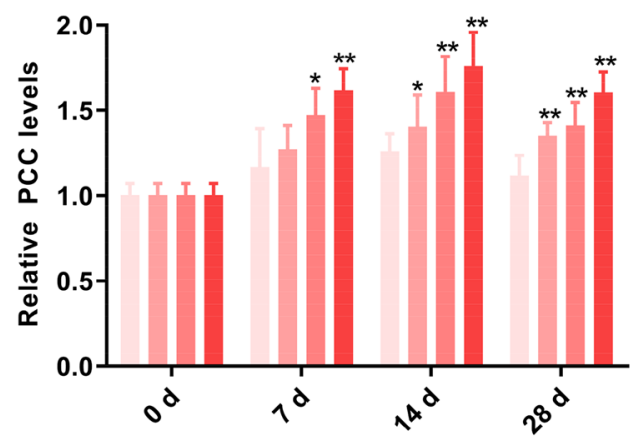

Exposure Time

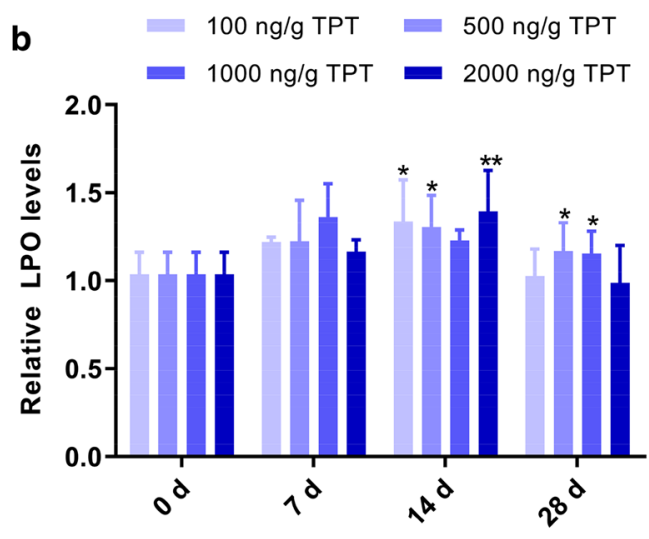

d

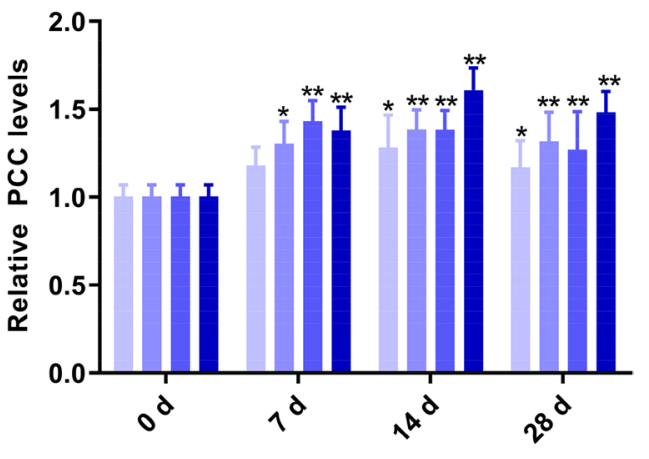

Exposure Time

Fig. 3 Relative levels of lipid peroxidation (LPO) in the hepatopancreas of Bellamya aeruginosa exposed to sediment-associated tributyltin (a) and triphenyltin (b) of 100, 500, 1000 and $2000 \mathrm{ng} / \mathrm{g}$. Relative level of protein carbonyl content (PCC) in the hepatopancreas of Bellamya aeruginosa exposed to sediment-associated tributyltin (c) and triphenyltin (d) of 100, 500, 1000 and $2000 \mathrm{ng} / \mathrm{g}$. Results are mean \pm SD. Asterisks indicate significant difference from the control $(p<0.05)$; double asterisks indicate significant difference from the control $(p<0.01)$
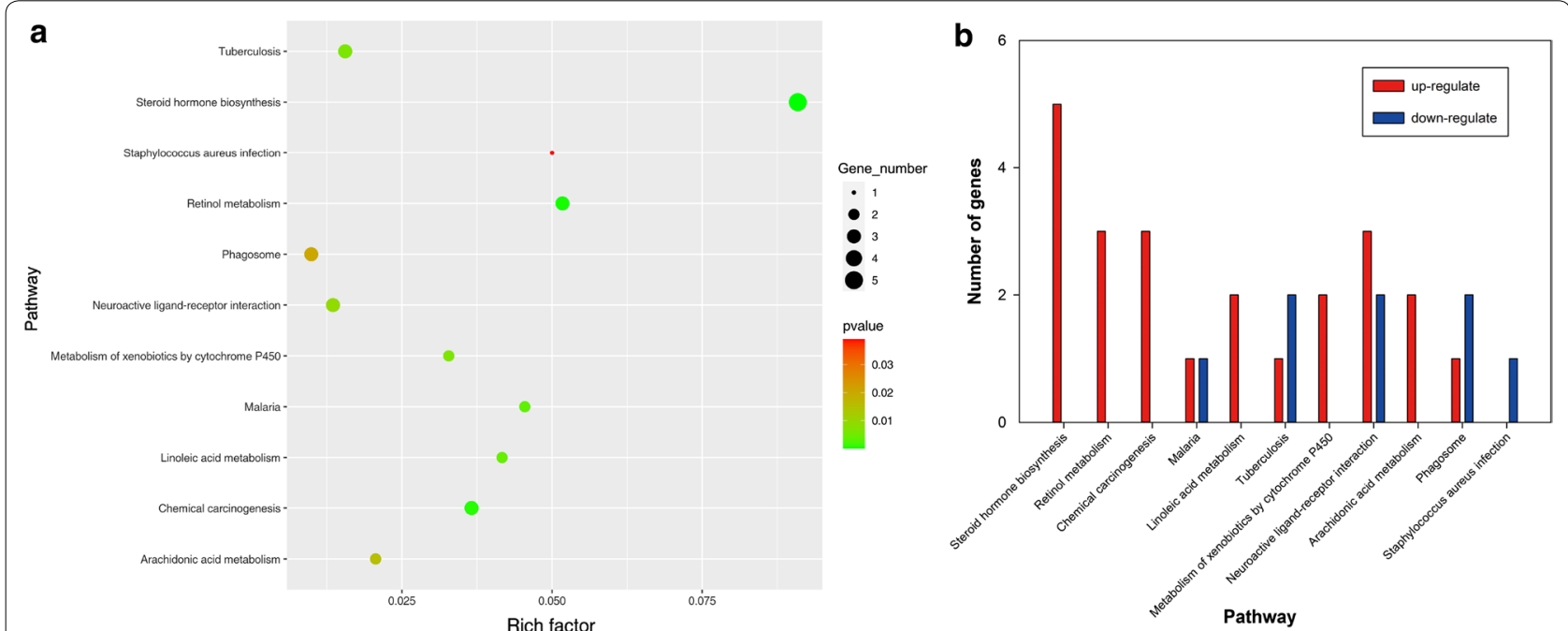

Fig. 4 Significant enrichment of Kyoto Encyclopedia of Genes and Genomes (KEGG) pathways for differentially expressed genes $(p<0.05)$ compared $2000 \mathrm{ng} / \mathrm{g}$ sediment-associated tributyltin exposure group with control group from Bellamya aeruginosa. a Bubble chart of pathway enrichment analysis of DEGs. $\mathbf{b}$ Enrichment analysis of up-regulated and down-regulated DEGs. The red bar represents the number of up-regulated genes in a pathway, and the blue bar represents the number of down-regulated genes in a pathway 
a range of $\log _{2} \mathrm{FC}$ from 1.37 to 9.72, while the remaining 868 DEGs were down-regulated with a range of $\log _{2}$ FC from -12.62 to -1.99 (data shown in Additional file 4). Up-regulated and down-regulated genes from TPT exposure group and control group were exhibited in a volcano plot, which is given in Additional file 5. Several DEGs related to metabolism, heat shock responses (heat shock protein), and immune response were identified. Seven genes involved in encoding CYP450, including CYP 1A1, CYP3A4, CYP3C, CYP5A, CYP3A and CYP9, which were significantly up-regulated.

KEGG pathway enrichment analyses were conducted for biological elucidation of DEGs. Total 263 annotated DEGs for TPT treatment group were functionally assigned to 20 KEGG pathways (Fig. 5). Among these KEGG pathways, the Ribosome pathway (ko03010) was the most enriched pathway, and followed by Protein processing in endoplasmic reticulum pathway (ko04141), Antigen processing and presentation pathway (ko04612). Above three pathways were inhibited with the downregulation of differentially expressed genes induced by sediment-associated TPT exposure in the $B$. aeruginosa. Fifty-one genes were down-regulated in the pathway of Ribosome. Genes down-regulated in the Protein processing in endoplasmic reticulum (Additional file 6: Table S1 and Fig. S1) include protein disulfide-isomerase (PDIs, EC:5.3.4.1), translocon-associated protein subunit alpha (TRAP), heat shock $70 \mathrm{kDa}$ (HSPA1s), molecular chaperone HtpG (Hsp 90A), crystallin (sHSF) and transitional endoplasmic reticulum ATPase (p97). Genes downregulated in the Antigen processing and presentation
(Additional file 6: Table S2 and Fig. S2) include heat shock $70 \mathrm{kDa}$ protein (HSPA1s), molecular chaperone HtpG (Hsp 90A), protein disulfide-isomerase (BRp57, EC:5.3.4.1) and cathepsin B (CTSB, EC:3.4.22.1).

\section{Discussion}

\section{Effects of tributyltin and triphenyltin on detoxification metabolism}

The cytochrome P450 system plays an essential role in the metabolism and excretion of pollutants and mediates the transformation of certain xenobiotics to reactive intermediates [43]. The cytochrome P450 activity can be induced or inhibited by many sorts of pollutants and is frequently measured in experimental organisms as a biological endpoint of exposure to environmental contaminants [44]. The debutylation of TBT in gastropods is mediated by cytochrome P450 enzymes [45]. In this study, EROD activities increased significantly after exposure to environmentally relevant concentrations of sediment-associated TBT or TPT for 7, 14 and 28 days. Padrós et al. [46] found that repeated exposure to $0.3 \mathrm{mg} / \mathrm{kg}$ TBT significantly induced hepatic P4501A activity in Salvelinus alpinus after 32 days. Similar results have been demonstrated with Sebastiscus marmoratus exposed to 1, 10 and $100 \mathrm{ng} / \mathrm{L}$ TBT [47]. It might be demonstrated that organotin compounds at dose do have the ability to induce hepatic P4501A activity. In this study, the relative EROD activity increased before day 14 and decreased at day 14 and 28 under the two lower treatments (100 and $500 \mathrm{ng} / \mathrm{g}$ TBT), while the relative EROD activity increased within all the exposure time at the two
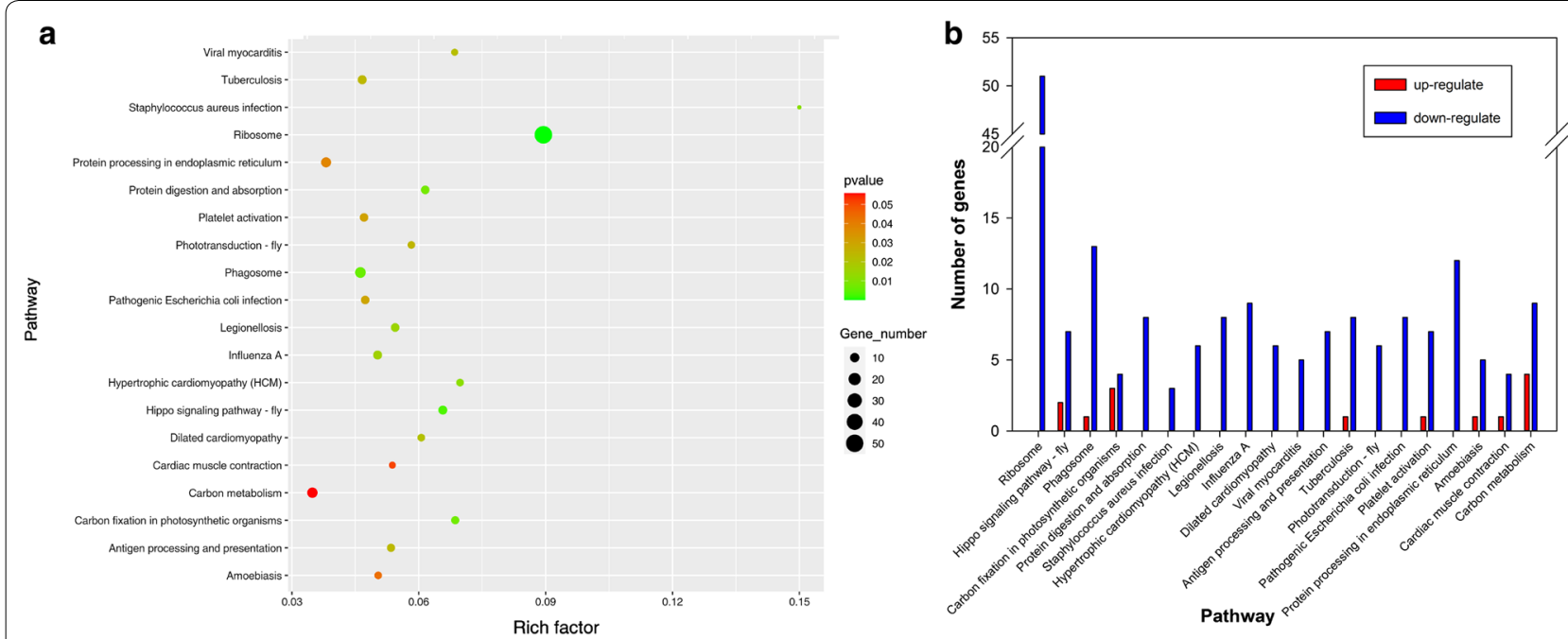

Fig. 5 Significant enrichment of Kyoto Encyclopedia of Genes and Genomes (KEGG) pathways for differentially expressed genes $(p<0.05)$ compared $2000 \mathrm{ng} / \mathrm{g}$ sediment-associated triphenyltin exposure group with control group from Bellamya aeruginosa. a Bubble chart of pathway enrichment analysis of DEGs. $\mathbf{b}$ Enrichment analysis of up-regulated and down-regulated DEGs. The red bar represents the number of up-regulated genes in a pathway, and the blue bar represents the number of down-regulated genes in a pathway 
higher treatment doses (1000 and $2000 \mathrm{ng} / \mathrm{g}$ TBT). The cytochrome P450 activity might be induced within all the exposure time because of the high concentrations of TBT. After exposure to the lowest treatment $(100 \mathrm{ng} / \mathrm{g}$ TPT), the relative EROD activity increased before day 14 and decreased at day 14 and 28 . The relative EROD activity increased within all the exposure times at the higher treatment dose (1000 ng/g TPT), while the relative EROD activity increased before day 14 and decreased at day 14 and 28 under the highest treatment dose $(2000 \mathrm{ng} / \mathrm{g}$ TPT). The highest concentration of TPT might have inhibited the cytochrome P450 activity with the increasing exposure time after day 14.

In the present study, EROD activities in snails exposed to $2000 \mathrm{ng} / \mathrm{g}$ TBT or TPT for 28 days were stimulated. The significant increase in EROD activity after a longer exposure to xenobiotic pollutants could be related to the promotion in the expression of CYP1A system. Mortensen and Arukwe [48] found that the expression of CYP1A1 was inhibited and the expression of CYP3A was induced at the transcriptional levels after exposure to increasing concentrations of TBT in juvenile salmon, which was confirmed by the immunochemical analysis of CYP3A and CYP1A1 protein levels. Cubero-Leon et al. [49] isolated two CYP3A-like genes from mussel (Mytilus edulis) and the expression of CYP3A-like isoform1 was significantly down-regulated after exposure to $100 \mathrm{ng} / \mathrm{L}$ TBT. In this study, exposure to TBT and TPT for 90 days both significantly up-regulate the expression of CYP1A1 and CYP3A4 genes in B. aeruginosa. These results suggested that inducible EROD activity and CYP genes are responsive to $\mathrm{TBT}$ and $\mathrm{TPT}$ contamination at the relative low concentrations. Therefore, EROD activity and the expression of CYP genes at the transcriptional level are sensitive biomarkers for the toxicity assessment of TBT and TPT in sediments.

\section{Toxicity of tributyltin and triphenyltin on hepatic antioxidant defense system}

SOD and CAT play critical roles in the antioxidant protection of invertebrates and induction of SOD and CAT activities indicates the formation of superoxide anions in the process of TBT or TPT metabolism. SOD is capable of catalyzing the dismutation reaction of $\mathrm{O}_{2}{ }^{-}$to form $\mathrm{H}_{2} \mathrm{O}_{2}$ and CAT converts $\mathrm{H}_{2} \mathrm{O}_{2}$ to $\mathrm{H}_{2} \mathrm{O}$ and $\mathrm{O}_{2}$. Asagba et al. [50] deemed that the decrease of SOD activity would be accompanied by the decrease of CAT activity as these two enzymes are linked functionally. In this study, both activities of SOD and CAT showed the most significant induction under $1000 \mathrm{ng} / \mathrm{g}$ TBT treatment group at day 14. After exposure to the highest treatment group (2000 ng/g TBT or $2000 \mathrm{ng} / \mathrm{g}$ TPT), SOD and CAT activities decreased from day 7 to day 28 , which was probably due to the poisonous effect of excess superoxide anion radical [51] and the destruction of native enzyme protein [52].

Oxidative stress is considered as a disturbance in the antioxidant system, which fails to adequately scavenge free radicals. As a major effect of free radicals, lipid peroxidation is a process by which oxygen combines with lipids to produce lipid hydroperoxides. Carbonyl can be formed in proteins which are attacked by free radicals and this process would cause a conformational change of proteins [53]. Protein carbonylation would result in breakdown of proteins by proteases due to the increased susceptibility to protease action [54]. In this study, significant increases of relative LPO levels indicated that the subchronic exposure of sediment-associated TBT or TPT at higher doses would result in lipid peroxidation. The significant increases of relative PCC levels suggested that exposure to TBT or TPT at concentrations higher than $500 \mathrm{ng} / \mathrm{g}$ led to oxidative damage in the hepatopancreas of $B$. aeruginosa.

\section{Comparative toxicity pathways of tributyltin and triphenyltin on $B$. aeruginosa}

In this study, high-throughput transcriptomic approach was implemented to explore the toxicity mechanisms of sediment-associated organotins at the environmentally relevant concentration on B. aeruginosa. A total of 392 and 1430 DEGs were identified for $2000 \mathrm{ng} / \mathrm{g}$ TBT and TPT exposure group, respectively. 169 genes that were differentially regulated in TBT compared to control were also differentially regulated in TPT (shown in Additional files 7 and 8). DEGs were significantly enriched in different pathways after exposure to $2000 \mathrm{ng} / \mathrm{g}$ TBT and TPT.

\section{Toxicity pathways of tributyltin}

The pathway of steroid hormone biosynthesis in B. aeruginosa was perturbed by sediment-bound TBT. Sex steroids are involved in regulating reproduction and sex differentiation in some invertebrates, and the critical steps of steroidogenesis producing androgens and estrogens have been demonstrated in mollusc and echinoderm species [55]. It is possible for certain chemicals to disturb endocrine homeostasis by which chemicals interfere with the synthesis or metabolism of sex steroids and affect steroid levels [56]. These endocrine-disrupting chemicals would target on key enzymes which are participated in the synthesis and metabolism of steroid hormone. Steroidogenic enzymes are composed of several specific cytochrome P450 enzymes (CYPs), hydroxysteroid dehydrogenases (HSDs) and steroid reductases, which regulate the conversion process from cholesterol to steroid hormones (e.g., progestins, androgens and estrogens) $[57,58]$. The enzyme aromatase (CYP19) plays 
an essential role in the final and rate-limiting step for converting androgens to estrogens. TBT is recognized as an endocrine-disrupting chemical by inhibiting aromatase (CYP19) activity. The androgen contents would be increased and the imposex would be caused in molluscs. Steroid hormone homeostasis is also affected by enzymes which regulate the metabolism of steroid hormones. Altered steroid metabolism is an essential mechanism of endocrine disruption caused by contaminants. Estrogens are synthesized in several different organs and metabolized throughout the whole body of $B$. aeruginosa $[59,60]$. 17 $\beta$-Hydroxysteroid dehydrogenase (17 $\beta$-HSD) dominates the final step in the formation of all androgens and all estrogens [61]. The weak estrogen estrone is converted to estradiol under the control of $17 \beta-\mathrm{HSD}$, and the balanced production of these estrogens depends on the activity of $17 \beta-$ HSD. Circulating estrogens, such as estrone and $17 \beta$-estradiol, are metabolized by direct conjugation to sulfate or by sulfate conjugation subsequent to hydroxylation by cytochrome P450 enzymes. CYP enzymes can hydroxylate estrogens at various positions to form 2,3- and 3,4-catechol estrogens, and estriol (16 $\alpha$-hydroxyestradiol) or 16 $\alpha$-hydroxyestrone. In this study, TBT might affect the estrogen metabolism in $B$. aeruginosa by inducing the expression of $17 \beta-\mathrm{HSD}$, CYP1A1, CYP3A and CYP3A4 genes. Alterations in steroid hormone metabolism often have connections with effects on steroid hormone-dependent processes including growth and reproduction [62]. Thus, the biological reactions of $17 \beta-$ HSD and CYP enzymes are involved in the mechanism of the pollutant tributyltin on hormonal disruption, which would cause subsequent reproductive and developmental toxicities [63-65].

The exposure of TBT pollution might disturb the retinoic acid degradation in B. aeruginosa. All-trans retinoic acid is a major active cellular metabolite of retinoid, and the synthesis of all-trans retinoic acid from all-trans retinol embodies in two steps, including the oxidation of retinol to retinal and the oxidation of retinal to retinoic acid [66]. The catabolism of all-trans retinoic acid is a vital mechanism for controlling the levels of retinoic acid. CYP1A1 and CYP3A are responsible for degrading retinoic acid into non-active molecules including 4-oxo retinoic acid and 18-OH retinoic acid [67]. In this study, the expression of CYP 1A1, CYP3A4 and CYP3A5 were all promoted which would increase the degradation of retinoic acid in B. aeruginosa after exposure to TBT. Zhang et al. [35] also found that the hepatic retinoic acid synthesis was decreased in rare minnow (Gobiocypris rarus) exposed to TBT. The retinoic acid homeostasis might be impaired which could cause abnormalities in many biological processes [68]. All-trans retinoic acid was demonstrated to inhibit the process of adipocyte differentiation and decrease adipogenesis early in the differentiation process [69]. Therefore, the adipogenesis might be promoted because of the decrease of retinoic acid. Dimastrogiovanni et al. [70] demonstrated that TBT, TPT and other endocrine disruptors could alter the gene expressions related to lipid metabolism. It has also been identified that both TBT and TPT are obesogenic compounds, promoting adipogenesis in 3T3-L1 cells [71] and improving fat deposition in neonate mice and frogs (Xenopus laevis) [72]. Therefore, in this study, TBT exposure might also disturb the regulation of adipogenesis in $B$. aeruginosa. Retinoic acid also exhibits great influence on reproduction. The inhibition of retinoic acid was demonstrated to disrupt spermatogenesis and fecundity [73], and decrease ovarian vitellogenesis in zebrafish [74]. Therefore, the disruption on the pathway of retinol metabolism in $B$. aeruginosa might also be involved in the toxic mechanisms of TBT on adipogenesis and reproduction.

\section{Toxicity pathways of triphenyltin}

More than $80 \%$ of intracellular proteins are degraded through the ubiquitin/proteasome-dependent pathway in eukaryotes $[75,76]$. In the protein processing in endoplasmic reticulum pathway, genes related to the protein degradation were down-regulated in this study, which might impair the ubiquitin proteasome system. Protein would accumulate in the endoplasmic reticulum, which might induce apoptosis. Shi et al. [77] found that TPT could inhibit the proteasome in the ubiquitin proteasome system, which contributed to the cellular toxicity. Thus, the ubiquitin proteasome system in Bellamya aeruginosa might be one of the molecular targets of triphenyltin.

Antigen processing and presentation are recognized as core elements of adaptive immunity. Antigens are processed and presented by accessories or antigen-presenting cells to specific lymphocytes through binding to major histocompatibility complex (MHC) I and II [78]. HSP70, HSP 90 and BRp57 genes play vital roles in MHC class I antigen processing and presentation. The BRp57 gene participates in the formation of the MHC class I. The peptide antigen is translocated across the endoplasmic reticulum (ER) membrane by the transporters TAP2 associated with antigen processing (TAP) and they will be loaded into the peptide-binding groove of MHC I in the lumen of the endoplasmic reticulum. Moreover, HSP70 and HSP90 are cytoplasmic proteins involved in the regulation of the antigen processing and presentation pathway. Cathepsin B (CTSB) makes contribution to antigen processing for presentation on MHC class II complex. T-cells become activated when the foreign antigen is presented by MHC molecules. In this study, TPT exposure down-regulated HSP70, HSP 90, BRp57 and CTSB genes, which would cause the inhibition of antigen processing 
and presentation. As a consequence, the immune system of $B$. aeruginosa may be impaired.

Based on the responses of $B$. aeruginosa to sedimentassociated TBT and TPT exposure from biochemical and genetic levels, underlying toxicity mechanisms of TBT and TPT at the same concentration were not the same. The expression of C-type lectins was significantly up-regulated and the pathway of phagosome was significantly enriched after exposure to TBT, which both implied the increase of immunity function [79]. Therefore, TBT altered the steroid hormone metabolism and disrupted the retinol metabolism, subsequently, induced immunity and oxidative stress. TPT disturbed the ribosome pathway, inhibited the ubiquitin proteasome system and impaired the immune system. In addition, DEGs identified for TPT were also enriched in pathways of steroid hormone biosynthesis $(p=0.12)$ and retinol metabolism $(p=0.13)$, which implied the potential of acting as an endocrine disruptor. Therefore, the toxicity of sedimentassociated TPT to snails $B$. aeruginosa was higher than TBT at the concentration of $2000 \mathrm{ng} / \mathrm{g}$ after 90 -day exposure. Zhang et al. $[80,81]$ also demonstrated that the lethality of Sebastiscus marmoratus exposed to $100 \mathrm{ng} / \mathrm{L}$ TPT was above $80 \%$ while that was $6.7 \%$ in the $100 \mathrm{ng} / \mathrm{L}$ TBT group. The reason for the difference might be the benzene ring in TPT or the higher bioconcentration factors of TPT in the aquatic organism [82].

\section{Conclusion}

In conclusion, a transcriptomic profile of $B$. aeruginosa exposed to tributyltin (TBT) and triphenyltin (TPT) was investigated for the first time. A total of 392 and 1430 differentially expressed unigenes were identified in snails after exposure to TBT and TPT, respectively. Subchronic exposure (28 days) of environmentally relevant concentrations of TBT or TPT could result in induction of antioxidant defense system and oxidative damage in the hepatopancreas of $B$. aeruginosa. CYP genes and EROD activity were sensible and reliable biomarkers for toxicity assessment of TBT or TPT in sediments. Comparative pathway analysis revealed the alteration of steroid hormone biosynthesis and retinol metabolism in B. aeruginosa after chronic exposure (90 days) to sediment-associated TBT at the environmentally relevant concentration $(2000 \mathrm{ng} / \mathrm{g} \mathrm{dw})$, which might affect both reproduction and lipogenesis functions. The ubiquitin proteasome system and immune system might be the toxicity target in $B$. aeruginosa after chronic exposure (90 days) to sediment-associated TPT. The results offered new mechanisms underlying the toxicity of sediment-associated TBT and TPT. The potential mechanisms provided by transcriptomics are deserved to be further validated by traditional biochemical assays.
Dose-dependent omics profiles can be explored to identify early responses at low dose range and the omicsbased biological pathway strategy will be a powerful tool for identifying potential toxicity of sediment-associated chemicals.

\section{Supplementary information}

Supplementary information accompanies this paper at https://doi. org/10.1186/s12302-020-00373-y.

Additional file 1. The annotation of DEGs between the tributyltin treatment group and the control group.

Additional file 2. The volcano plot indicating up-regulated and downregulated genes from tributyltin exposure group and control group.

Additional file 3: Fig. S1. The KEGG pathway analysis for steroid hormone biosynthesis pathway DEGs expressed in response to 2000 $\mathrm{ng} / \mathrm{g}$ sediment-associated tributyltin exposure in Bellamya aeruginosa. Red squares represent up-regulated genes. Fig. S2. The KEGG pathway analysis for retinol metabolism pathway DEGs expressed in response to $2000 \mathrm{ng} / \mathrm{g}$ sediment-associated tributyltin exposure in Bellamya aeruginosa. Red squares represent up-regulated genes. Table S1. Steroid hormone biosynthesis pathway genes regulated in response to $2000 \mathrm{ng} / \mathrm{g}$ sediment-associated TBT exposure in hepatopancreas of Bellamya aeruginosa. Table S2. Retinol metabolism pathway genes regulated in response to $2000 \mathrm{ng} / \mathrm{g}$ sediment-associated TBT exposure in hepatopancreas of Bellamya aeruginosa.

Additional file 4. The annotation of DEGs between the control group and triphenyltin treatment group.

Additional file 5. The volcano plot indicating up-regulated and downregulated genes from triphenyltin exposure group and control group.

Additional file 6: Fig. S1. The KEGG pathway analysis for protein processing in endoplasmic reticulum pathway DEGs expressed in response to 2000 ng/g sediment-associated triphenyltin exposure in Bellamya aeruginosa. Green squares represent down-regulated genes. Fig. S2. The KEGG pathway analysis for antigen processing and presentation pathway DEGs expressed in response to $2000 \mathrm{ng} / \mathrm{g}$ sediment-associated triphenyltin exposure in Bellamya aeruginosa. Green squares represent down-regulated genes. Table S1. Protein processing in endoplasmic reticulum pathway genes regulated in response to $2000 \mathrm{ng} / \mathrm{g}$ sediment-associated triphenyltin exposure in hepatopancreas of Bellamya aeruginosa. Table S2. Antigen processing and presentation pathway genes regulated in response to 2000 ng/g sediment-associated triphenyltin exposure in hepatopancreas of Bellamya aeruginosa.

Additional file 7. Heat map of all transcripts.

Additional file 8. A Venn diagram showing the number of transcripts differing significantly expressed in TBT exposure group and TPT exposure group as compared to control group.

\section{Abbreviations}

TBT: Tributyltin; TPT: Triphenyltin; B. aeruginosa: Bellamya aeruginosa; ROS: Reactive oxygen species; EROD: Ethoxyresorufin-O-deethylase; SOD: Superoxide dismutase; CAT: Catalase; LPO: Lipid peroxidation; PCC: Protein carbonyls content; $\mathrm{H}_{2} \mathrm{O}_{2}$ : Hydrogen peroxide; HTS: High-throughput sequencing; RNA-seq: RNA sequencing; TBTCl: Tributyltin chloride; TPTCl: Triphenyltin chloride; REA: Relative enzyme activity; ANOVA: Analysis of variance; PCR: Polymerase chain reaction; KEGG: Kyoto Encyclopedia of Genes and Genomes; GO: Gene ontology; DEGs: Differentially expressed genes; RSEM: RNA-seq by expectationmaximization; SULT2B1: Alcohol sulfotransferase; HSD17B1: 17beta-estradiol 17-dehydrogenase; CYP1A1: Cytochrome P450 family 1 subfamily A polypeptide 1; CYP3A: Cytochrome P450 family 3 subfamily A; CYP3A4: Cytochrome P450 family 3 subfamily A polypeptide 4; CYP3A5: Cytochrome P450 family 3 subfamily A polypeptide 5; PDIs: Protein disulfide-isomerase; TRAP: Transloconassociated protein subunit alpha; HSPA1s: Heat shock 70 kDa; Hsp 90A: 
Molecular chaperone HtpG; sHSF: Crystallin; p97: Transitional endoplasmic reticulum ATPase; BRp57: Protein disulfide-isomerase; CTSB: Cathepsin B; 17ß-HSD: 17ß-Hydroxysteroid dehydrogenase; ER: Endoplasmic reticulum; TAP: Antigen processing; MHC: Major histocompatibility complex.

\section{Acknowledgements}

We are thankful to the Foundation of National Special Item on Water Resource and Environment (No. 2017ZX07603003) and the Fundamental Research Funds for the Central Universities (No. 22120180243) for their financial support.

\section{Authors' contributions}

LW and QL conceived and designed the experiments. QL wrote the manuscript. QL, LZ and XC made contributions to the biochemical analysis. QL made contributions to the transcriptomic analysis. LW and LC made substantial contributions to the interpretation of data and the revision of the manuscript. All authors read and edited the manuscript and agree with its publication in a scientific journal. All authors read and approved the final manuscript.

\section{Funding}

This work was supported by the Foundation of National Special Item on Water Resource and Environment (No. 2017ZX07603003) and the Fundamental Research Funds for the Central Universities (No. 22120180243).

\section{Availability of data and materials}

The datasets supporting the conclusions of this article are included within the article and its additional file.

\section{Ethics approval and consent to participate}

Not applicable.

\section{Consent for publication}

Not applicable.

\section{Competing interests}

The authors declare that they have no competing interests.

\section{Author details}

1 Key Laboratory of Yangtze River Water Environment, Ministry of Education, College of Environmental Science and Engineering, Tongji University, Shanghai 200092, China. ${ }^{2}$ Shanghai Institute of Pollution Control and Ecological Security, Shanghai 200092, China.

Received: 6 February 2020 Accepted: 28 June 2020

Published online: 08 July 2020

\section{References}

1. Batista-Andrade JA, Caldas SS, Batista RM, Castro IB, Fillmann G, Primel EG (2018) From TBT to booster biocides: levels and impacts of antifouling along coastal areas of Panama. Environ Pollut 234:243-252

2. Lutfi E, Riera-Heredia N, Córdoba M, Porte C, Gutiérrez J, Capilla E, Navarro I (2017) Tributyltin and triphenyltin exposure promotes in vitro adipogenic differentiation but alters the adipocyte phenotype in rainbow trout. Aquat Toxicol 188:148-158

3. Li ZF, Yu DG, Gong WB, Wang GJ, Yu EM, Xie J (2019) Aquatic ecotoxicology and water quality criteria of three organotin compounds: a review. Nat Environ Pollut Technol 18:217-224

4. Toste R, Fernandez MA, Pessoa IDA, Parahyba MA, Dore MP (2011) Organotin pollution at Arraial Do Cabo, Rio De Janeiro State, Brazil: increasing levels after the TBT ban. Braz J Oceanogr 59:111-117

5. Castro IB, Arroyo MF, Costa PG, Fillmann G (2012) Butyltin compounds and imposex levels in Ecuador. Arch Environ Contam Toxicol 62:68-77

6. Anastasiou TI, Chatzinikolaou E, Mandalakis M, Arvanitidis C (2016) Imposex and organotin compounds in ports of the Mediterranean and the Atlantic: is the story over? Sci Total Environ 569-570:1315-1329

7. Batista RM, Castro IB, Fillmann G (2016) Imposex and butyltin contamination still evident in Chile after TBT global ban. Sci Total Environ 566-567:446-453
8. Kim NS, Hong SH, Yim UH, Shin KH, Shim WJ (2014) Temporal changes in TBT pollution in water, sediment, and oyster from Jinhae Bay after the total ban in South Korea. Mar Pollut Bull 86:547-554

9. Huang CJ, Dong QX, Lie Z, Wang ZX, Zhou K (2005) An investigation of organotin compound contamination in three harbors along southeast coast of China. Acta Oceanol Sin 27:57-63

10. Chen CZ, Chen L, Xue R, Huang QH, Wu LL, Ye SF, Zhang W (2019) Spatiotemporal variation and source apportionment of organotin compounds in sediments in the Yangtze Estuary. Environ Sci Eur 31:24

11. Sousa A, Laranjeiro F, Takahashi S, Tanabe S, Barroso CM (2009) Imposex and organotin prevalence in a European post-legislative scenario: temporal trends from 2003 to 2008. Chemosphere 77:566-573

12. Tessier E, Amouroux D, Morin A, Christian L, Thybaud E, Vindimian E, Donard OFX (2007) (Tri)Butyltin biotic degradation rates and pathways in different compartments of a freshwater model ecosystem. Sci Total Environ 388:214-233

13. Yang MY, Lu KL, Batzer DP, Wu HT (2019) Freshwater release into estuarine wetlands changes the structure of benthic invertebrate assemblages: a case study from the Yellow River Delta. Sci Total Environ 687:752-758

14. Schmitt C, Oetken M, Dittberner O, Wagner M, Oehlmann J (2008) Endocrine modulation and toxic effects of two commonly used UV screens on the aquatic invertebrates Potamopyrgus antipodarum and Lumbriculus variegatus. Environ Pollut 152:322-329

15. Hecker M, Hollert H (2011) Endocrine disruptor screening: regulatory perspectives and needs. Environ Sci Eur 23:15

16. Colborn T, Vom Saal FS, Soto AM (1993) Developmental effects of endocrine-disrupting chemicals in wildlife and humans. Environ Health Perspect 101:378-384

17. Titley-O'Neal CP, Munkittrick KR, MacDonald BA (2011) The effects of organotin on female gastropods. J Environ Monit 13:2360-2388

18. Laranjeiro F, Sánchez-Marín P, Oliveira IB, Galante-Oliveira S, Barroso C (2018) Fifteen years of imposex and tributyltin pollution monitoring along the Portuguese coast. Environ Pollut 232:411-421

19. Yin HB, Cai YJ, Duan HT, Gao JF, Fan CX (2014) Use of DGT and conventional methods to predict sediment metal bioavailability to a field inhabitant freshwater snail (Bellamya aeruginosa) from Chinese eutrophic lakes. J Hazard Mater 264:184-194

20. Yin G, Zhou YH, Strid A, Zheng ZY, Bignert A, Ma TW, Athanassiadis I, Qiu YL (2017) Spatial distribution and bioaccumulation of polychlorinated biphenyls (PCBs) and polybrominated diphenyl ethers (PBDEs) in snails (Bellamya aeruginosa) and sediments from Taihu Lake area, China. Environ Sci Pollut Res 24:7740-7751

21. Ma TW, Gong SJ, Zhou K, Zhu C, Deng KD, Luo QH, Wang ZJ (2010) Laboratory culture of the freshwater benthic gastropod Bellamya aeruginosa (Reeve) and its utility as a test species for sediment toxicity. J Environ Sci 22:304-313

22. Wernersson AS, Carere M, Maggi C, Tusil P, Soldan P, James A, Sanchez W, Dulio V, Broeg K, Reifferscheid G, Buchinger S, Maas H, Grinten EVD, O'Toole S, Ausili A, Manfra L, Marziali L, Polesello S, Lacchetti I, Mancini L, Lilja K, Linderoth M, Lundeberg T, Fjällborg B, Porsbring T, Larsson DGJ, Bengtsson-Palme J, Förlin L, Kienle C, Kunz P, Vermeirssen E, Werner I, Robinson CD, Lyons B, Katsiadaki I, Whalley C, Haan KD, Messiaen M, Clayton H, Lettieri T, Carvalho RN, Gawlik BM, Hollert H, Paolo CD, Brack W, Kammann U, Kase R (2015) The European technical report on aquatic effect-based monitoring tools under the water framework directive. Environ Sci Eur 27:7

23. Zanette J, Monserrat JM, Bianchini A (2015) Biochemical biomarkers in barnacles Balanus improvisus: pollution and seasonal effects. Mar Environ Res 103:74-79

24. Lushchak VI (2011) Environmentally induced oxidative stress in aquatic animals. Aquat Toxicol 101:13-30

25. Monserrat JM, Martínez PE, Geracitano LA, Amado LL, Martins CMG, Pinho GLL, Chaves IS, Ferreira-Cravo M, Ventura-Lima J, Bianchini A (2007) Pollution biomarkers in estuarine animals: critical review and new perspectives. Comp Biochem Physiol C 146:221-234

26. Itziou A, Dimitriadis VK (2011) Introduction of the land snail Eobania vermiculata as a bioindicator organism of terrestrial pollution using a battery of biomarkers. Sci Total Environ 409:1181-1192

27. Bourlat SJ, Borja A, Gilbert J, Taylor MI, Davies N, Weisberg SB, Griffith JF, Lettieri T, Field D, Benzie J, Glöckner FO, Rodríguez-Ezpeleta N, Faith DP, Bean TP, Obst M (2013) Genomics in marine monitoring: 
new opportunities for assessing marine health status. Mar Pollut Bull 74:19-31

28. Xia P, Zhang HX, Peng Y, Shi W, Zhang XW (2020) Pathway-based assessment of single chemicals and mixtures by a high-throughput transcriptomics approach. Environ Int 136:105455

29. Ekblom R, Galindo J (2011) Applications of next generation sequencing in molecular ecology of non-model organisms. Heredity 107:1-15

30. Brinkmann M, Koglin S, Eisner B, Wiseman S, Hecker M, Eichbaum K, Thalmann B, Buchinger S, Reifferscheid G, Hollert H (2016) Characterisation of transcriptional responses to dioxins and dioxin-like contaminants in roach (Rutilus rutilus) using whole transcriptome analysis. Sci Total Environ 541:412-423

31. Zhao XL, Yu H, Kong LF, Li Q (2012) Transcriptomic responses to salinity stress in the Pacific oyster Crassostrea gigas. PLoS ONE 7:e46244

32. Jiang X, Qiu LG, Zhao HW, Song QQ, Zhou HL, Han Q, Diao XP (2016) Transcriptomic responses of Perna viridis embryo to Benzo(a)pyrene exposure elucidated by RNA sequencing. Chemosphere 163:125-132

33. Ankley G, Bennett R, Erickson R, Hoff D, Hornung M, Johnson R (2010) Adverse outcome pathways: a conceptual framework to support ecotoxicology research and risk assessment. Environ Toxicol Chem 29:730-741

34. Garcia-Reyero N, Perkins E (2011) Systems biology: leading the revolution in ecotoxicology. Environ Toxicol Chem 30:265-553

35. Zhang JL, Zhang CN, Sun P, Huang MX, Fan MZ, Liu M (2017) RNAsequencing and pathway analysis reveal alteration of hepatic steroid biosynthesis and retinol metabolism by tributyltin exposure in male rare minnow (Gobiocypris rarus). Aquat Toxicol 188:109-118

36. Li Q, Wang M, Duan L, Qiu YL, Ma TW, Chen L, Magnus B, Ake B, Zhao JF, Markus H, Wu LL (2018) Multiple biomarker responses in caged benthic gastropods Bellamya aeruginosa after in situ exposure to Taihu Lake in China. Environ Sci Eur 30:34

37. Ma TW, Gong SJ, Tian B (2017) Effects of sediment-associated CuO nanoparticles on $\mathrm{Cu}$ bioaccumulation and oxidative stress responses in freshwater snail Bellamya aeruginosa. Sci Total Environ 580:797-804

38. OECD (2004) OECD guidelines for the testing of chemicals: sedimentwater chironomid toxicity test using spiked sediment

39. Chen $Z Y$, Chen $L$, Chen CZ, Huang QH, Wu LL, Zhang W (2017) Organotin contamination in sediments and aquatic organisms from the Yangtze estuary and adjacent marine environments. Environ Eng Sci 34:227-235

40. Hou JL, Zhuang P, Chen L, Wu LL (2011) Hepatic specific antioxidant responses in Pelteobagrus fulvidraco following a short-term exposure to phenanthrene. Fresen Environ Bull 20:1230-1235

41. Robinson MD, McCarthy DJ, Smyth GK (2010) edgeR: a Bioconductor package for differential expression analysis of digital gene expression data. Bioinformatics 26:139-140

42. Nätt $D$, Rubin $C J$, Wright $D$, Johnsson M, Beltéky J, Andersson $L$, Jensen $P(2012)$ Heritable genome-wide variation of gene expression and promoter methylation between wild and domesticated chickens. BMC Genomics 13:59

43. Oliva M, Gravato C, Guilhermino L, Galindo-Riano MD, Perales JA (2014) EROD activity and cytochrome P4501A induction in liver and gills of Senegal sole Solea senegalensis from a polluted Huelva Estuary. Comp Biochem Phys 166:134-144

44. Li MH (2016) Development of in vivo biotransformation enzyme assays for ecotoxicity screening: in vivo measurement of phases I and II enzyme activities in freshwater planarians. Ecotoxicol Environ Saf 130:19-28

45. Fent K (1996) Ecotoxicology of organotin compounds. Crit Rev Toxicol 26:3-117

46. Padrós J, Pelletier E, Ribeiro CO (2003) Metabolic interactions between low doses of benzo[a]pyrene and tributyltin in arctic charr (Salvelinus alpinus): a long-term in vivo study. Toxicol Appl Pharmacol 192:45-55

47. Wang Y (2007) Toxicological effects of benzo[a]pyrene, tributyltin and their mixture to Sebastiscus marmoratus. Dissertation, Xiamen University

48. Mortensen AS, Arukwe A (2007) Modulation of xenobiotic biotransformation system and hormonal responses in Atlantic salmon (Salmo salar) after exposure to tributyltin (TBT). Comp Biochem Phys C 145:431-441

49. Cubero-Leon E, Puinean AM, Labadie P, Ciocan C, Itoh N, Kishida M, Osada M, Minier C, Hill EM, Rotchell JM (2012) Two CYP3A-like genes in the marine mussel Mytilus edulis: mRNA expression modulation following short-term exposure to endocrine disruptors. Mar Environ Res 74:32-39
50. Asagba SO, Eriyamremu GE, Igberaese ME (2008) Bioaccumulation of cadmium and its biochemical effect on selected tissues of the catfish (Clarias gariepinus). Fish Physiol Biochem 34:61-69

51. Zheng SM, Wang YY, Zhou QX, Chen CH (2013) Responses of oxidative stress biomarkers and DNA damage on a freshwater snail (Bellamya aeruginosa) stressed by ethylbenzene. Arch Environ Contam Toxicol 65:251-259

52. Wang CG, Chen YX, Li Y, Wei W, Yu Q (2005) Effects of low dose tributyltin on activities of hepatic antioxidant and phase II enzymes in Sebastiscus marmoratus. Bull Environ Contam Toxicol 74:114-119

53. Gopalakrishnan S, Nai Z, Thilagam H, Bei C, Ding J, Wang XH, Wang WX, Ke CH, Giesy JP, Zhang XW, Wang KJ (2011) Biochemical responses and DNA damage in red sea bream from coastal Fujian Province, China. Ecotoxicol Environ Saf 74:1526-1535

54. Zhang $X$, Yang F, Zhang $X, X u Y$, Liao T, Song S, Wang H (2008) Induction of hepatic enzymes and oxidative stress in Chinese rare minnow (Gobiocypris rarus) exposed to waterborne hexabromocyclododecane (HBCDD). Aquat Toxicol 86:4-11

55. Janer G, Porte C (2007) Sex steroids and potential mechanism of non-genomic endocrine disruption in invertebrates. Ecotoxicology 16:145-160

56. Castro-Català ND, López-Doval J, Gorga M, Petrovic M, Muñoz I (2013) Is reproduction of the snail Physella acuta affected by endocrine disrupting compounds? An in situ bioassay in three Iberian basins. J Hazard Mater 263P:248-255

57. Miller WL (1988) Molecular biology of steroid hormone synthesis. Endocr Rev 9:295-318

58. Sanderson JT (2006) The steroid hormone biosynthesis pathway as a target for endocrine-disrupting chemicals. Toxicol Sci 94:3-21

59. Lei K, Liu RZ, An LH, Luo YF, LeBlanc GA (2015) Estrogen alters the profile of the transcriptome in rive snail Bellamya aeruginosa. Ecotoxicology 24:330-338

60. Shore J (2018) Estradiol: a steroid with multiple facets. Horm Metab Res 50:359-374

61. Labrie F, Luu-The V, Lin SX, Labrie C, Simard J, Breton R, Belanger A (1997) The key role of $17 \beta$-hydroxysteroid dehydrogenases in sex steroid biology. Steroids 62:148-158

62. Parks LG, LeBlanc GA (1996) Reduction on steroid hormone biotransformation/elimination as a biomarker of pentachlorophenol chronic toxicity. Aquat Toxicol 34:291-303

63. Sanderson JT, Seinen W, Giesy JP, Berg MVD (2000) 2-Chloro-s-triazine herbicides induce aromatase (CYP19) activity in H295R human adrenocortical carcinoma cells: a novel mechanism for estrogenicity? Toxicol Sci 54:121-127

64. Barata C, Porte C, Baird DJ (2004) Experimental designs to assess endocrine disrupting effects in invertebrates A review. Ecotoxicology 13:511-517

65. Sanderson T (2006) Pesticides and the disruption of the enzyme aromatase. Outlooks Pest Manage 17:21-23

66. Blomhoff R, Blomhoff HK (2006) Overview of retinoid metabolism and function. J Neurobiol 66:606-630

67. Marill J, Idres N, Capron CC, Nguyen E, Chabot GG (2003) Retinoic acid metabolism and mechanism of action: a review. Curr Drug Metab 4:1-10

68. Frey SK, Vogel S (2011) Vitamin A metabolism and adipose tissue biology. Nutrients 3:27-39

69. Moon HS, Guo DD, Song HH, Kim IY, Jin HL, Kim YK, Chung CS, Choi YJ, Lee HK, Cho CS (2007) Regulation of adipocyte differentiation by PEGylated all-trans retinoic acid: reduced cytotoxicity and attenuated lipid accumulation. J Nutr Biochem 18:322-331

70. Dimastrogiovanni G, Córdoba M, Navarro I, Jáuregui O, Porte C (2015) Alteration of cellular lipids and lipid metabolism markers in RTL-W1 cells exposed to model endocrine disrupters. Aquat Toxicol 165:277-285

71. Kanayama T, Kobayashi N, Mamiya S, Nakanishi T, Nishikawa JI (2005) Organotin compounds promote adipocyte differentiation as agonists of the peroxisome proliferator-activated receptor gamma/retinoid X receptor pathway. Mol Pharmacol 67:766-774

72. Grün F, Watanabe H, Zamanian Z, Maeda L, Arima K, Cubacha R, Gardiner DM, Kanno J, Iguchi T, Blumberg B (2006) Endocrine-disrupting organotin compounds are potent inducers of adipogenesis in vertebrates. Mol Endocrinol 20:2141-2155 
73. Pradhan A, Olsson PE (2015) Inhibition of retinoic acid synthesis disrupts spermatogenesis and fecundity in zebrafish. Gen Comp Endocrinol 217-218:81-91

74. Levi I, Ziv T, Admon A, Levavi-Sivan B, Lubzens E (2012) Insight into molecular pathways of retinal metabolism, associated with vitellogenesis in zebrafish. Am J Physiol Endocrinol Metab 302:E626-E644

75. Ciechanover A (1998) The ubiquitin-proteasome pathway: on protein death and cell life. EMBO J 17:7151-7160

76. Dou QP, Li B (1999) Proteasome inhibitors as potential novel anticancer agents. Drug Resist Update 2:215-223

77. Shi GQ, Chen D, Zhai GS, Chen MS, Cui QC, Zhou QF, He B, Dou QP, Jiang GB (2009) The proteasome is a molecular target of environmental toxic organotins. Environ Health Perspect 117:379-386

78. Vyas JM, Van der Veen AG, Ploegh HL (2008) The known unknowns of antigen processing and presentation. Nat Rev Immunol 8:607-618

79. Hu FX, Pan LQ, Cai YF, Liu T, Jin Q (2015) Deep sequencing of the scallop Chlamys farreri transcriptome response to tetrabromobisphenol A (TBBPA) stress. Mar Genomics 19:31-38
80. Zhang JL, Zuo ZH, He CY, Cai JL, Wang YQ, Chen YX, Wang CG (2009) Effects of tributyltin on testicular development in Sebastiscus marmoratus and the mechanism involved. Environ Toxicol Chem 28:1528-1535

81. Zhang JL, Wang ZB, Zhu WW, Sun P, Xiong JL (2013) Effects of triphenyltin on ovarian development in Sebastiscus marmoratus. Mar Fish 35:41-46 (in Chinese)

82. Tsuda T, Aoki S, Kojima M, Harada H (1990) Differences between freshwater and seawater-acclimated guppies in the accumulation and excretion of tributyltin chloride and triphenyltin chloride. Water Res 24:1373-1376

\section{Publisher's Note}

Springer Nature remains neutral with regard to jurisdictional claims in published maps and institutional affiliations.

\section{Submit your manuscript to a SpringerOpen ${ }^{\circ}$ journal and benefit from:}

- Convenient online submission

- Rigorous peer review

- Open access: articles freely available online

- High visibility within the field

- Retaining the copyright to your article

Submit your next manuscript at $\gg$ springeropen.com 